\title{
Microstructural Characterization of Melt Extracted High-Nb-Containing TiAl-Based Fiber
}

\author{
Shuzhi Zhang ${ }^{1,2}$, Shuling Zhang ${ }^{3}$, Yanfei Chen ${ }^{4}$, Jianchao Han ${ }^{5}$, Changjiang Zhang ${ }^{1,2}$, \\ Xiaopeng Wang ${ }^{6, *}$ and Yuyong Chen ${ }^{6}$ \\ 1 School of Materials Science and Engineering, Taiyuan University of Technology, Taiyuan 030024, China; \\ zhshzh1984@163.com (S.Z.); zcj0408@163.com (C.Z.) \\ 2 Shanxi Key Laboratory of Advanced Magnesium-based Materials, Taiyuan University of Technology, \\ Taiyuan 030024, China \\ 3 School of Mechanical Engineering, Ningxia University, Ningxia 750021, China; slzhang1229@163.com \\ 4 Ningbo Branch of China Ordnance Academy, Ningbo 315000, China; yanfeichen@hotmail.com \\ 5 School of Mechanical Engineering, Taiyuan University of Technology, Taiyuan 030024, China; \\ hanjianchao@tyut.edu.cn \\ 6 National Key Laboratory for Precision Hot Processing of Metals, Harbin Institute of Technology, \\ Harbin 150001, China; yychen@hit.edu.cn \\ * Correspondence: wangxiaopeng@hit.edu.cn; Tel.: +86-351-6010022
}

Academic Editor: Javier Narciso

Received: 24 December 2016; Accepted: 14 February 2017; Published: 17 February 2017

\begin{abstract}
The microstructure of melt extracted Ti-44Al-8Nb-0.2W-0.2B-1.5Si fiber were investigated. When the rotation speed increased from 2000 to $2600 \mathrm{r} / \mathrm{min}$, the appearance of the wire was uniform with no Rayleigh-wave default. The structure was mainly composed of fine $\alpha_{2}(\alpha)$ phase dendritic crystal and a second phase between dendrite arms and grain boundaries. The precipitated second phases were confirmed to be $\mathrm{Ti}_{5} \mathrm{Si}_{3}$ from the eutectic reaction $\mathrm{L} \rightarrow \mathrm{Ti}_{5} \mathrm{Si}_{3}+\alpha$ and $\mathrm{TiB}$. As the lower content of $\mathrm{Si}$ and higher cooling rate, a divorced eutectic microstructure was obtained. Segregation of $\mathrm{Ti}, \mathrm{Nb}, \mathrm{B}, \mathrm{Si}$, and $\mathrm{Al}$ occurred during rapid solidification.
\end{abstract}

Keywords: intermetallics; rapid-solidification; melt extracted; $\mathrm{Ti}_{5} \mathrm{Si}_{3}$; divorced eutectic; TEM

\section{Introduction}

Due to the low density, high specific strength, elastic modulus, and oxidation resistance at high temperatures, $\gamma$-TiAl-based alloys have been considered as strong candidates for high-temperature structural applications in aerospace and automotive industries [1-3]. However, the poor hot workability and low room temperature ductility severely restrict their application [4,5]. Many efforts have been performed to enhance the mechanical properties, such as adding alloying elements [6,7], heat treatment [8], and thermomechanical treatment $[9,10]$. However, as the most effective method, thermomechanical treatment can only refine the grain size to the range of 5-10 $\mu \mathrm{m}$ and is always difficult to completely break down $\alpha_{2} / \gamma$ lamellar structures [11,12].

Rapid solidification (RS) process could significantly refine grain size, produce metastable, and novel structures, increases solubility of alloying elements and reduce levels of segregation [13-15]. RS has been performed on binary TiAl alloys by different methods [16]. For RS, a single roller melt-spinning technique with circumferential velocities of $10-30 \mathrm{~m} / \mathrm{s}$ has been utilized to produce TiAl ribbons $[17,18]$. However, the ribbon thickness, which affects cooling rate, is easily influenced by the melt temperature, and the mechanical properties of ribbon is limited by the defects of the surface $[19,20]$. Melt extraction is another melt spinning technique, which could prepare metallic fiber or ceramic fiber with diameters less than $30 \mu \mathrm{m}$, and a detailed description of this method is 
elsewhere [21]. Melt extraction not only allows access to relatively reactive metals, such as aluminum, titanium, zirconium, and magnesium, but also makes the fabrication of high temperature ceramics relatively easy [21,22]. Additionally, the cooling rate of melt extraction can reach about $106 \mathrm{~K} / \mathrm{s}$ which is usually higher than other RS techniques $[20,23]$.

$\mathrm{Si}$ element can enhance the creep resistance by forming the finer eutectoid $\mathrm{Ti}_{5} \mathrm{Si}_{3}$ phase, which has been well studied under conventional cast TiAl alloys [24]. However, the effect of RS on the solid solubility of $\mathrm{Si}$ and the formation of silicide in TiAl alloy has not been fully understood. Additional, the primary phase of TiAl alloy fabricated by single roller melt-spinning technique was $\beta$ phase [18]. As the higher cooling rate of melt extraction than other RS technique, greater undercooling which strongly influences the primary phase and solidification path can be obtained.

The aim of this work was to investigate the microstructure characterization and prior phase of TiAl fiber under higher cooling rates fabricated by melt extraction. The formation of second phase, especially $\mathrm{Ti}_{5} \mathrm{Si}_{3}$ and its distribution were studied. In addition, the element segregation during rapid solidification was also investigated.

\section{Experimental}

Ti-44Al-8Nb-0.2W-0.2B-1.5Si alloy was fabricated by a Vacuum Arc Remelting furnace (120/200, Jinzheng Metallurgical Technology Corporation, Shenyang, China), with dimensions of $\phi 110 \mathrm{~mm} \times 140 \mathrm{~mm}$, and subsequently hot isostatic pressed (HIPed) at $1300{ }^{\circ} \mathrm{C} / 130 \mathrm{MPa}$ for $3 \mathrm{~h}$ under argon atmosphere. The raw materials were sponge titanium (99.9 $\mathrm{wt} \%)$, pure $\mathrm{Al}(99.99 \mathrm{wt} \%)$, pure $\mathrm{Si}(99.9 \mathrm{wt} \%), \mathrm{Al}-\mathrm{Nb}(\mathrm{Nb}: 50.9 \mathrm{wt} \%)$ master alloy, Al-W (W: wt \%) master alloy, and B (99.7 wt \%) crystals. The Ti-44Al-8Nb-0.2W-0.2B-1.5Si alloy ingots were cut into $10 \mathrm{~mm}$ in diameter and $10 \mathrm{~mm}$ in length by the electrical discharge machine. TiAl alloy fibers were prepared by the melt extraction technique using a copper wheel with diameter of $160 \mathrm{~mm}$. The rotation speed of the copper wheel was 2000 and $2600 \mathrm{r} / \mathrm{min}$, and the feed rate of the molten alloy is about $70 \mu \mathrm{m} / \mathrm{s}$.

The morphology of fiber was characterized by scanning electron microscopy (SEM) in a TESCAN MIRA3 LMH field-emission scanning electron microscope (Tescan, Brno, Czech Republic). Microstructures were also observed via transmission electron microscopy (TEM) in a FEI Talos F200 $\times$ field-emission environmental transmission electron microscope (FEI, Hillsboro, OR, USA). Specimens for TEM were cross-sectioned by focused ion beam (FIB, HELIOS NanoLab 600i, FEI).

\section{Results}

The different geometrical morphologies of fibers produced with different rotation speeds of the copper wheel are shown in Figure 1. The fiber fabricated with a rotation speed of $2000 \mathrm{r} / \mathrm{min}$ was of heterogeneous appearance which was the result of the instability of the extracted molten metal (Figure 1a). With the rotation speed increased to $2600 \mathrm{r} / \mathrm{min}$, the appearance of the wire was uniform with no Rayleigh-wave default, shown in Figure 1b. Compared with higher rotate speed, as the decrease of rotate speed, the liquid metal cylinder which is under the effect of surface tension and its own weight is in its unstable state and forms a Rayleigh-wave default. Figure 1c is the XRD result of wire fabricated with rotation speed of $2600 \mathrm{r} / \mathrm{min}$. It was revealed that the dominant phase of wire was $\alpha$ phase, with $\mathrm{Ti}_{5} \mathrm{Si}_{3}$ as one of the second phase. The microstructure subsequent studied was sampling from wires with a rotation speed of $2600 \mathrm{r} / \mathrm{min}$. 

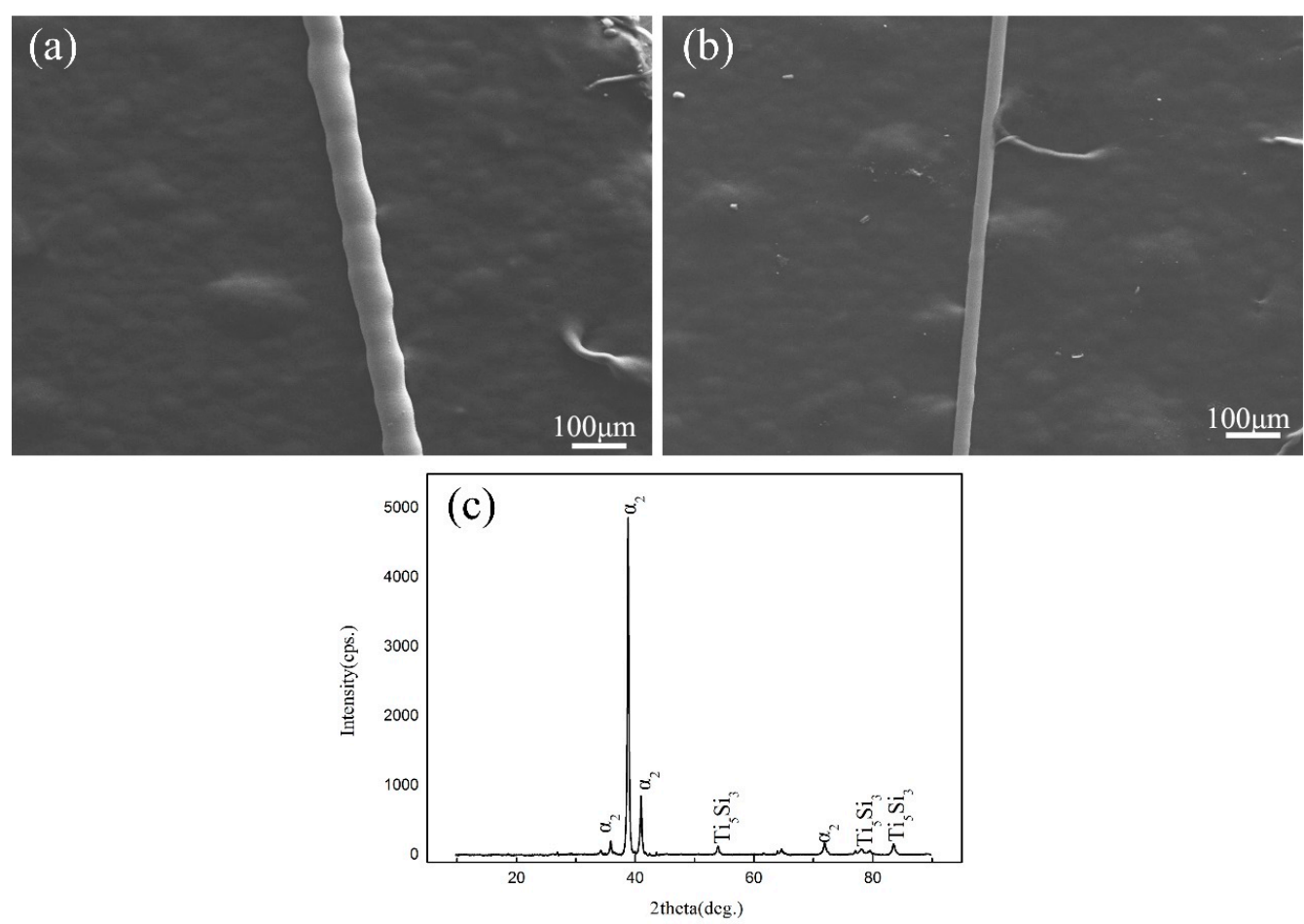

Figure 1. SEM micrograph of fibers with different rotation speeds and XRD results of fibers: (a) $2000 \mathrm{r} / \mathrm{min}$; (b) $2600 \mathrm{r} / \mathrm{min}$; (c) XRD results of fibers.

The microstructure of fibers was analyzed by TEM, Figure 2. As is shown in Figure 2a, there existed two different microstructural morphologies which had been divided by red dotted line. The structure on the left side was mainly composed of fine dendritic crystal and second phases located between the dendrite arms and at grain boundaries (Figure 2a), which is totally different from that of ribbons fabricated by RS technique [18]. The selected area diffraction (SAD) revealed that the dendrites were $\alpha_{2}-\mathrm{Ti}_{3} \mathrm{Al}$ (Figure 2), and the second phase were $\mathrm{Ti}_{5} \mathrm{Si}_{3}$ which were confirmed by HRTEM. The microstructure on the right side of Figure 2a away from the wheel contact surface of wire was a mixture structure of $\alpha_{2}$ and $\mathrm{Ti}_{5} \mathrm{Si}_{3}$, has no dentrite morphology, shown in the right side of Figure $2 \mathrm{~b}$. SAD illustrated that not all the $\alpha$ phase has ordered into $\alpha_{2}$ phase (Figure $2 \mathrm{c}, \mathrm{d}$ ).

In order to understand the distribution of elements, EDS mapping was carried out of the RS Ti-44Al-8Nb-0.2W-0.2B-1.5Si alloy, Figure 3 EDS results revealed that W element was homogeneous in distribution. As a $\beta$ phase stabilizing element, $W$ segregated in $\beta$ phase at grain boundaries during conventional solidification. Compared with conventional solidification, the RS technique has improved the solubility of $\mathrm{W}$ element in $\alpha_{2}$ phase. On the contrary, the elements $\mathrm{Ti}, \mathrm{Al}, \mathrm{Nb}, \mathrm{B}$, and $\mathrm{Si}$ were significantly segregated. $\mathrm{The} \mathrm{Ti}, \mathrm{Nb}, \mathrm{B}$, and $\mathrm{Si}$ elements were segregated to the second phase between the dendrite arms and along grain boundaries. The second phase in the dendritic arms and along grain boundaries was enriched with $\mathrm{Ti}$ and $\mathrm{Si}$, but without $\mathrm{Al}$, and $\mathrm{Si}$ element was only interdendritic, but $\mathrm{Al}$ element enriched the matrix phase ( $\alpha$ phase or $\alpha_{2}$ phase). Si and B segregated to different phase, Figure 3f,g. 

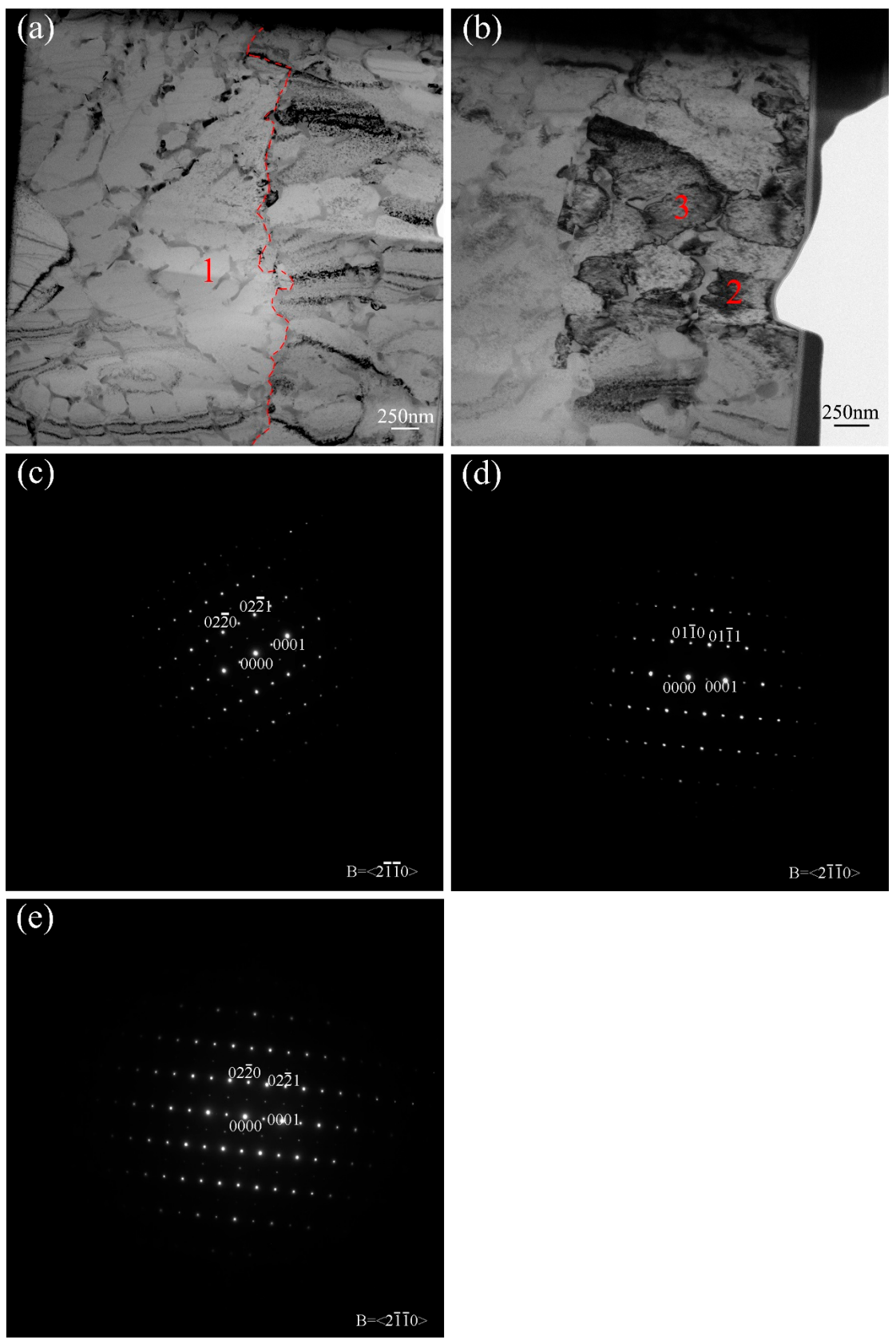

Figure 2. Cross-sectional TEM micrographs of the wires. (a,b) are the bright field images; $(\mathbf{c}-\mathbf{e})$ are the selected area diffraction patterns of regions in (a) and (b) marked by number 1,2 , and 3 . Wheel contact surface is on the left of $(a, b)$.

The further study of the second phase was carried out by TEM, as shown in Figure 4. Figure 4a shows the morphology and the distribution of second phase. HRTEM was performed to study the region marked by the blue arrow in Figure 4a, and the FFT graph of this area is revealed by Figure 4c. As is shown by Figure 4a, the length of the phase indicated by arrow is no more than $200 \mathrm{~nm}$. The precipitated second phase was confirmed as $\mathrm{Ti}_{5} \mathrm{Si}_{3}$ by HRTEM and the corresponding FFT result. In order to further understand the morphology of the B enriched phase, Figure $4 \mathrm{~d}$, a bright field image was carried out. The $\mathrm{B}$ enriched phase with a rod-like shape always precipitated accompanying $\mathrm{Ti}_{5} \mathrm{Si}_{3}$ along grain boundaries. As the small size of the B-rich phase, the diffraction spot in the FFT image could not be used to analyses the crystal structure, shown in Figure 4e,f. However, TiB is the only boride produced in TiAl based alloy when B element is lower [22]. 

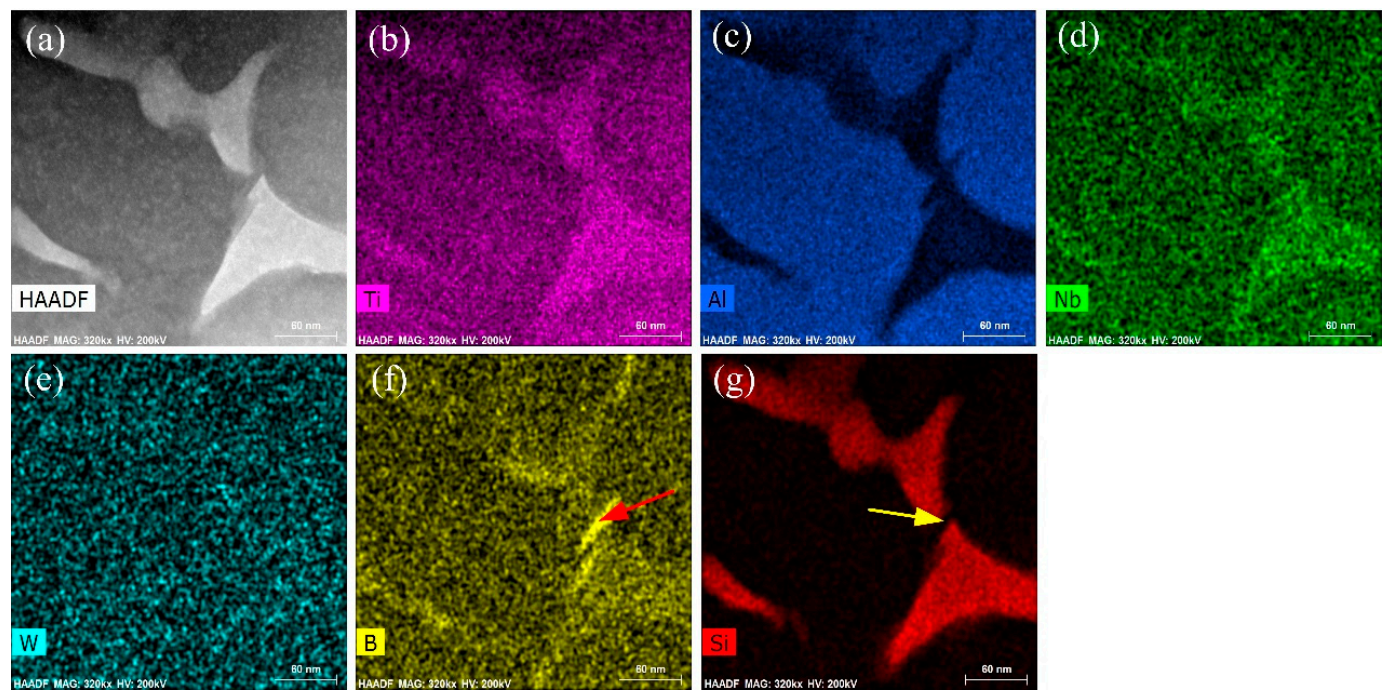

Figure 3. EDS chemical mapping of RS Ti-44Al-8Nb-0.2W-0.2B-1.5Si alloy: (a) The corresponding STEM-HADDF image; (b) Ti-K $\alpha$; (c) Al-K $\alpha$; (d) Nb-K $\alpha$; (e) W-K $\alpha$; (f) B-K $\alpha$; and (g) Si-K $\alpha$.
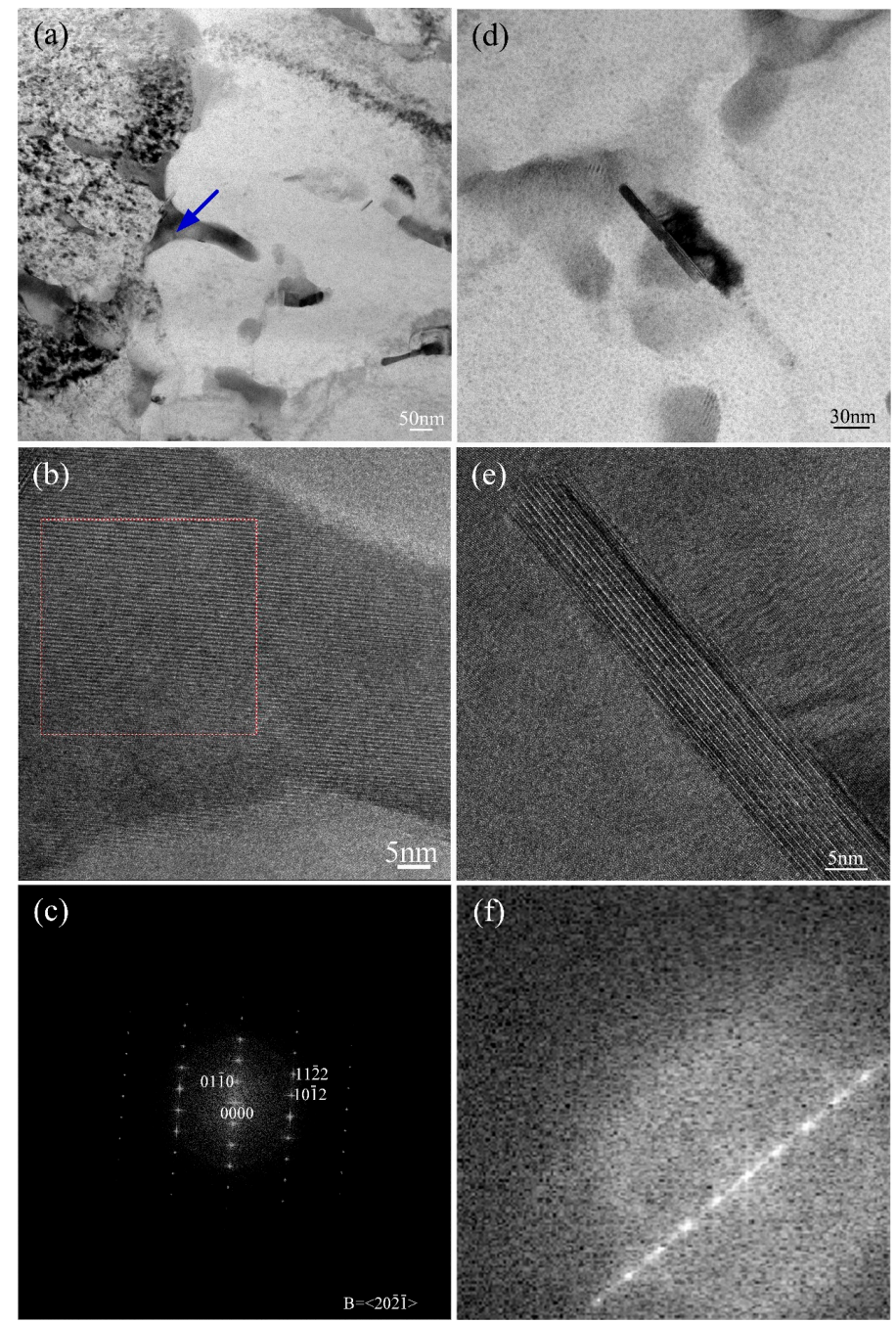

Figure 4. TEM micrographs of second phases: $(\mathbf{a}, \mathbf{d})$ are bright field images; $(\mathbf{b}, \mathbf{c})$ are the HRTEM and FFT of the region marked by blue arrow in (a); (e,f) are the HRTEM and FFT of the rod-like phase in (b). 


\section{Discussion}

According to the analysis above, the main phase of RSTi-44Al-8Nb-0.2W-0.2B-1.5Si fiber was $\alpha_{2}(\alpha)$, was totally different from the conventional casting which is typically $\beta$ phase solidification alloy with a $\beta$ phase as primary phase [25]. When the rotation speed reached $2600 \mathrm{r} / \mathrm{min}$, the high undercooling resulting from the high cooling rate of RS is beneficial to the formation of primary $\alpha$ phase $[18,26]$. Compared to Ti-48Al-2Cr alloy strip obtained by single roller melt-spinning technique, there was no $\beta$ phase in the structure ofTi- $44 \mathrm{Al}-8 \mathrm{Nb}-0.2 \mathrm{~W}-0.2 \mathrm{~B}-1.5 \mathrm{Si}$ alloy wires becuase the cooling rate of melt extraction technique is higher than that of single roller melt-spinning technique [18]. Although the solid solubility of $\mathrm{Si}$ in $\alpha$ phase could reach up to 15 at \%, the presence of $\mathrm{Nb}$ element, which is a strong silicide former reduced the solubility for $\mathrm{Si}$ in the $\alpha_{2}-\mathrm{Ti}_{3} \mathrm{Al}$ phase [24,27]. Si was ejected into the melt during rapid solidification, and formed silicide at the solid-liquid interface between $\alpha$ phase and liquid. As revealed by Figure $2 b-d$, not all the high temperature $\alpha$ phase has transformed into its ordered state $\alpha_{2}$ phase, and there still exists $\alpha$ phase which is probably the result of rapid cooling rate. Meanwhile, TiB has also been detected in the microstructure of Ti- $44 \mathrm{Al}-8 \mathrm{Nb}-0.2 \mathrm{~W}-0.2 \mathrm{~B}-1.5 \mathrm{Si}$ wires.

$\mathrm{Ti}_{5} \mathrm{Si}_{3}$ distributed at the dendrite arms is the primary second phase in the structure of Ti-44Al-8Nb-0.2W-0.2B-1.5Si wires. As illustrated by Sun, primary large isolated $\mathrm{Ti}_{5} \mathrm{Si}_{3}$, eutectic morphology $\mathrm{Ti}_{5} \mathrm{Si}_{3}$ whisker $\left(\mathrm{L} \rightarrow \mathrm{Ti}_{5} \mathrm{Si}_{3}+\alpha\right)$ and eutectoid $\mathrm{Ti}_{5} \mathrm{Si}_{3}\left(\alpha \rightarrow \mathrm{Ti}_{5} \mathrm{Si}_{3}+\gamma\right)$ had been found in TiAl alloy with different Si containing [28]. With the decrease of temperature and the changes of melt constituent after the formation of primary $\alpha$ phase $\left(\alpha_{p}\right)$ of RS TiAl alloy wires, a eutectic transformation of $\mathrm{L} \rightarrow \mathrm{Ti}_{5} \mathrm{Si}_{3}+\alpha$ took place $\left(\alpha_{\mathrm{e}}\right)$. For the Si content is merely 1.5 at $\%$, a large volume fraction of $\alpha_{\mathrm{p}}$ is acquired before the eutectic transformation. That is to say, hypoeutectic microstructure could obtain. As is shown in Figure 2, the high cooling rate changes the morphology of hypoeutectic microstructure to divorced eutectic which has the morphology that the eutectic $\mathrm{Ti}_{5} \mathrm{Si}_{3}$ was separated along $\alpha$ phase grain boundaries rather than formed eutecticum. Divorced eutectic could be obtained under the condition of alloy composition is far away from eutectic point or non-equilibrium solidification (e.g., higher cooling rate) $[29,30]$. The divorced eutectic has no longer had the alternate characteristic of eutectic structure and has the two phase separated with each other. The $\alpha_{\mathrm{e}}$ phase nucleated on the interface of $\alpha_{\mathrm{p}}$ phase and then grown up, and the eutectic $\mathrm{Ti}_{5} \mathrm{Si}_{3}$ phase was push out to the grain boundary of the $\alpha_{\mathrm{p}}$ phase. Based on the Ti-Al-B ternary phase diagram, alloy with the composition of Ti-44Al-0.2B has the final microstructure of $\alpha_{2}+\gamma+$ TiB2, and TiB2 was the stable boride [31]. However, the phase composition of RS Ti-44Al-8Nb-0.2W-0.2B-1.5Si alloy was $\alpha\left(\alpha_{2}\right)$ and TiB which is the stabilized boride. Two reasons could be in consider, on the one hand, RS has caused the phase field which the solidification microstructure located in shifting left towards the lower aluminum content on the equilibrium phase diagram. That is to say, the microstructure of Ti-44Al-8Nb-0.2W-0.2B-1.5Si changed from $\alpha_{2}+\gamma+$ TiB2 to $\alpha\left(\alpha_{2}\right)+$ TiB. On the other hand, as $\beta$ stabilizing elements, $\mathrm{Nb}$ and $\mathrm{W}$ strongly influenced the solidification path, and then $\mathrm{TiB}$ was the stable boride in the microstructure of RS Ti-44Al-8Nb-0.2W-0.2B-1.5Si alloy. As reported by $\mathrm{Hu}$, the formation of $\mathrm{TiB}$ at solid-liquid interface is beneficial to the formation of alpha phase [32,33]. However, in the microstructure of this RSTi-44Al-8Nb-0.2W-0.2B-1.5Si wire, TiB is not as nucleus of $\alpha$ phase. It is maybe the reason why TiB could not be as the nucleus of $\alpha$ phase is that the volume fraction of $\alpha_{p}$ phase is large and then the later $\alpha$ phase forms in the remnant melt at the position of the interface between $\alpha_{p}$ phase and remnant melt rather than at the position of TiB. This nucleation mode has lower interfacial energy and distortion energy than that of the nucleation with TiB.

\section{Conclusions}

RS Ti-44Al-8Nb-0.2W-0.2B-1.5Si wire was fabricated by melt extraction technique. The appearance of the wire was fine and uniform when the rotation speed increased to $2600 \mathrm{r} / \mathrm{min}$. TEM analysis revealed that the structure is mainly composed of fine dendritic crystal and second phase $\left(\mathrm{Ti}_{5} \mathrm{Si}_{3}\right.$ and $\left.\mathrm{TiB}\right)$ between dendrite arms and at grain boundaries. As the result of high cooling rate, $\alpha$ phase nucleated as primary phase, and some $\alpha$ phase was remain rather than ordered into $\alpha_{2}$ phase. 
The formation of $\mathrm{Ti}_{5} \mathrm{Si}_{3}$ is the result of the eutectic transformation of $\mathrm{L} \rightarrow \mathrm{Ti}_{5} \mathrm{Si}_{3}+\alpha$. However, for the hypoeutectic microstructure and higher cooling rate, a divorced eutectic microstructure was obtained. The solubility of $\mathrm{W}$ element in $\alpha_{2}$ phase was improved by RS, but the segregation of $\mathrm{Ti}, \mathrm{Nb}, \mathrm{B}, \mathrm{Si}$, and $\mathrm{Al}$ was not obviously influenced by the cooling rate. $\mathrm{TiB}$ is the only boride containing in the microstructure of RS Ti-44Al-8Nb-0.2W-0.2B-1.5Si alloy.

Acknowledgments: This work was financially supported by the National Natural Science Foundation of China (Nos. 51604159, 51604191, 51504163), the State Key Laboratory for Advanced Metal and Materials Foundation (Nos. 2014-ZD06), the financial support of the Ningbo Natural Science Foundation (Grant No. 2016A610243), and the Natural Science Funds, Ningxia (Grant No. NZ15038). We also thank the Youth Foundation of Taiyuan University of Technology (Nos. 2015QN014), and the Qualified Personnel Foundation of Taiyuan University of Technology (Nos. tyut-rc201342a and tyut-rc201343a).

Author Contributions: Xiaopeng Wang and Yuyong Chen conceived and designed the experiments; Shuling Zhang performed the experiments; Shuzhi Zhang wrote the paper. Yanfei Chen contributed analysis tools; Janchao Han and Changjiang Zhang analyzed the data.

Conflicts of Interest: The authors declare no conflict of interest.

\section{References}

1. Zhang, T.; Wu, Z.; Hu, R.; Zhang, F.; Kou, H.; Li, J. Influence of nitrogen on the microstructure and solidification behavior of high Nb containing TiAl alloys. Mater. Des. 2016, 103, 100-105. [CrossRef]

2. Shen, Z.Z.; Lin, J.P.; Liang, Y.F.; Zhang, L.Q.; Shang, S.L.; Liu, Z.K. A novel hot pack rolling of high $\mathrm{Nb}-\mathrm{TiAl}$ sheet from cast ingot. Intermetallics 2015, 67, 19-25. [CrossRef]

3. Han, J.; Xiao, S.; Tian, J.; Chen, Y.; Xu, L.; Wang, X.; Jia, Y.; Rahoma, H.K.S.; Du, Z.; Cao, S. Microstructure characterization, mechanical properties and toughening mechanism of TiB2-containing conventional cast TiAl-based alloy. Mater. Sci. Eng. A 2015, 645, 8-19. [CrossRef]

4. Rashkova, B.; Spiradek-Hahn, K.; Brabetz, M.; Zhang, Z.L.; Schoberl, T.; Clemens, H.; Mayer, S. Microstructural evolution and grain refinement in an intermetallic titanium aluminide alloy with a high molybdenum content. Int. J. Mater. Res. 2015, 106, 725-731. [CrossRef]

5. Klein, T.; Schachermayer, M.; Mendez-Martin, F.; Schöberl, T.; Rashkova, B.; Clemens, H.; Mayer, S. Carbon distribution in multi-phase $\gamma$-TiAl based alloys and its influence on mechanical properties and phase formation. Acta Mater. 2015, 94, 205-213. [CrossRef]

6. Imayev, R.M.; Imayev, V.M.; Oehring, M.; Appel, F. Alloy design concepts for refined gamma titanium aluminide based alloys. Intermetallics 2007, 15, 451-460. [CrossRef]

7. Kartavykh, A.V.; Asnis, E.A.; Piskun, N.V.; Statkevich, I.I.; Gorshenkov, M.V.; Tcherdyntsev, V.V. Lanthanum hexaboride as advanced structural refiner/getter in TiAl-based refractory intermetallics. J. Alloys Compd. 2014, 588, 122-126. [CrossRef]

8. Schwaighofer, E.; Clemens, H.; Mayer, S.; Lindemann, J.; Klose, J.; Smarsly, W.; Güther, V. Microstructural design and mechanical properties of a cast and heat-treated intermetallic multi-phase $\gamma$-TiAl based alloy. Intermetallics 2014, 44, 128-140. [CrossRef]

9. Schwaighofer, E.; Clemens, H.; Lindemann, J.; Stark, A.; Mayer, S. Hot-working behavior of an advanced intermetallic multi-phase $\gamma$-TiAl based alloy. Mater. Sci. Eng. A 2014, 614, 297-310. [CrossRef]

10. Cui, N.; Kong, F.; Wang, X.; Chen, Y.; Zhou, H. Microstructural evolution, hot workability, and mechanical properties of Ti-43Al-2Cr-2Mn-0.2Y alloy. Mater. Des. 2016, 89, 1020-1027. [CrossRef]

11. Zhang, S.Z.; Kong, F.T.; Chen, Y.Y.; Liu, Z.Y.; Lin, J.P. Phase transformation and microstructure evolution of differently processed Ti-45Al-9Nb-Y alloy. Intermetallics 2012, 31, 208-216. [CrossRef]

12. Dong, S.; Chen, R.; Guo, J.; Ding, H.; Su, Y.; Fu, H. Deformation behavior and microstructural evolution of directionally solidified TiAlNb-based alloy during thermo-compression at 1373-1573 K. Mater. Des. 2015, 84, 118-132.

13. Huang, S.-C.; Hall, E.L. Characterization of the effect of vanadium additions to TiAl base alloys. Acta Metall. Mater. 1991, 39, 1053-1060. [CrossRef]

14. Shao, G.; Grosdidier, T.; Tsakiropoulos, P. The metastable disordered $\gamma$ (TiAl) phase and its ordering process in a rapidly solidified equiatomic TiAl alloy with vanadium addition. Scr. Metall. Mater. 1994, 30, 809-814. [CrossRef] 
15. Karaköse, E.; Keskin, M. Effect of solidification rate on the microstructure and microhardness of a melt-spun Al-8Si-1Sb alloy. J. Alloys Compd. 2009, 479, 230-236. [CrossRef]

16. Liu, Y.C.; Yang, G.C.; Guo, X.F.; Huang, J.; Zhou, Y.H. Coupled growth behavior in the rapidly solidified Ti-Al peritectic alloys. J. Cryst. Growth 2001, 222, 645-654. [CrossRef]

17. Liu, Z.G.; Chai, L.H.; Chen, Y.Y.; Kong, F.T.; Davies, H.A.; Figueroa, I.A. Microstructure evolution in rapidly solidified $Y$ added TiAl ribbons. Intermetallics 2011, 19, 160-164. [CrossRef]

18. Zhu, D.; Dong, D.; Ni, C.; Zhang, D.; Zhou, Z.; Wang, H.; Wei, Z. Effect of wheel speed on the microstructure and nanohardness of rapidly solidified Ti-48Al-2Cr alloy. Mater. Charact. 2015, 99, 243-247. [CrossRef]

19. Phan, M.-H.; Peng, H.-X. Giant magnetoimpedance materials: Fundamentals and applications. Prog. Mater. Sci. 2008, 53, 323-420. [CrossRef]

20. Ström-Olsen, J. Fine fibres by melt extraction. Mater. Sci. Eng. A 1994, 178, 239-243. [CrossRef]

21. Wang, H.; Xing, D.; Wang, X.; Sun, J. Fabrication and characterization of melt-extracted Co-based amorphous wires. Metall. Mater. Trans. A 2011, 42, 1103-1108. [CrossRef]

22. Allahverdi, M.; Drew, R.A.L.; Strom-Olsen, J.O. Melt-extracted oxide ceramic fibers-The fundamentals. J. Mater. Sci. 1996, 31, 1035-1042. [CrossRef]

23. Ma, X.Z.; Shen, J.; Jia, J. Study on rare earth-containing phases in TiAl based alloys prepared by non-equilibrium solidification processing. J. Rare Earth 2001, 2, 103-106.

24. Klein, T.; Rashkova, B.; Holec, D.; Clemens, H.; Mayer, S. Silicon distribution and silicide precipitation during annealing in an advanced multi-phase $\gamma$-TiAl based alloy. Acta Mater. 2016, 110, 236-245. [CrossRef]

25. Yang, G.; Kou, H.; Yang, J.; Li, J.; Fu, H. Microstructure control of Ti45Al8.5Nb(W, B, Y) alloy during the solidification process. Acta Mater. 2016, 112, 121-131. [CrossRef]

26. Huang, S.-C.; Hall, E.L. The effects of Cr additions to binary TiAl-base alloys. Metall. Trans. A 1991, 22, 2619-2627. [CrossRef]

27. Dezellus, O.; Gardiola, B.; Andrieux, J.; Lomello-Tafin, M.; Viala, J.C. On the liquid/solid phase equilibria in the Al-rich corner of the Al-Si-Ti ternary system. J. Ph. Equilib. Diffus. 2014, 35, 137-145. [CrossRef]

28. Sun, F.-S.; Froes, F.H. Solidification behavior of $\mathrm{Ti}_{5} \mathrm{Si}_{3}$ whiskers in TiAl alloys. Mater. Sci. Eng. A 2003, 345, 262-269. [CrossRef]

29. Yan, N.; Geng, D.L.; Hong, Z.Y.; Wei, B. Ultrasonic levitation processing and rapid eutectic solidification of liquid Al-Ge alloys. J. Alloys Compd. 2014, 607, 258-263. [CrossRef]

30. Dahle, A.K.; Lee, Y.C.; Nave, M.D.; Schaffer, P.L.; St John, D.H. Development of the as-cast microstructure in magnesium-aluminium alloys. J. Light Met. 2001, 1, 61-72. [CrossRef]

31. Witusiewicz, V.T.; Bondar, A.A.; Hecht, U.; Zollinger, J.; Artyukh, L.V.; Velikanova, T.Y. The Al-B-Nb-Ti system: V. Thermodynamic description of the ternary system Al-B-Ti. J. Alloys Compd. 2009, 474, 86-104. [CrossRef]

32. Hu, D.; Yang, C.; Huang, A.; Dixon, M.; Hecht, U. Solidification and grain refinement in Ti45Al2Mn2Nb1B. Intermetallics 2012, 22, 68-76. [CrossRef]

33. Hu, D.; Yang, C.; Huang, A.; Dixon, M.; Hecht, U. Grain refinement in beta-solidifying Ti44Al8Nb1B. Intermetallics 2012, 23, 49-56. [CrossRef]

(C) 2017 by the authors; licensee MDPI, Basel, Switzerland. This article is an open access article distributed under the terms and conditions of the Creative Commons Attribution (CC BY) license (http:/ / creativecommons.org/licenses/by/4.0/). 